\title{
Correlation between nutritional, hematological and infectious characteristics and classification of the type of epidermolysis bullosa of patients assisted at the Dermatology Clinic of the Hospital Universitário de Brasília*
}

\author{
Márcia Carolline dos Santos Sousa ${ }^{1}$ \\ Pedro Luiz Tauil ${ }^{1}$
}

\author{
Carmen Dea Ribeiro de Paula ${ }^{1}$ \\ Izelda Maria Carvalho Costa ${ }^{1}$
}

DOI: http:/ /dx.doi.org/10.1590/abd1806-4841.20154575

\begin{abstract}
Epidermolysis bullosa comprises a group of phenotypically different genodermatosis, hereditary or acquired, characterized by skin fragility and subsequent formation of blisters in response to mechanical trauma, and which may also affect mucous membranes. This study aimed to analyze the relation between the nutritional, hematologic, infectious characteristics and the type of epidermolysis bullosa, through a descriptive case study based on data from medical records of 10 patients with epidermolysis bullosa assisted regularly at the Dermatology Clinic of the Hospital Universitário de Brasília. The old classification of the type of epidermolysis bullosa, weight and height, blood count, white blood cell count, platelet count and description of the type and frequency of secondary infections during the service were considered. We verified a predominance of iron deficiency anemia, chronic leukocytosis, thrombocytosis, chronic malnutrition, low height for age and thinness, and people with epidermolysis bullosa simplex exhibited appropriate relation between height/age and BMI/age. The nonspecific skin infection was the most prevalent in both sexes. The severity of the type of epidermolysis bullosa and frequency of secondary infections did not form a directly proportional relation. The absence of direct proportion in all cases between the type of epidermolysis bullosa and the analysis parameters suggest a possible significant interference from other aspects such as the extent of the affected skin area, extracutaneous type of engagement and specific genetic mutation. The inclusion of these factors in the new classification proposed by Fine et al can contribute significantly to a better correlation of clinical parameters and appropriate preventive and therapeutic approaches.
\end{abstract}

Keywords: Child nutrition; Epidermolysis bullosa; Infection

Epidermolysis bullosa (EB) is a group of phenotypically different genodermatosis, hereditary or acquired, characterized by skin fragility and subsequent formation of blisters in response to mechanical trauma, which may also affect mucous membranes.

${ }^{1-3}$ Due to the severe forms of disease and its high risk of infection, the mortality rate between affected newborns is high. ${ }^{1-3}$ Children with EB may suffer delayed growth and puberty, which often are linked to low food intake, justified by the difficulty in swallowing or anemia. ${ }^{4} \mathrm{~EB}$ is a rare disease with great variability in incidence and prevalence, and, in Brazil, epidemiological data are poorly understood. ${ }^{3}$

According to the recent proposal of Fine et al, the classification of EB can be compared with the layers of an onion, and the first step is the inclusion with-

Approved by the Advisory Board and accepted for publication on 22.09.2015

Study performed at Ambulatório de Dermatologia do Hospital Universitário de Brasília - Universidade de Brasília (HUB-UnB) - Brasília (DF), Brazil. Financial Support: None.

Conflict of Interest: None.

Universidade de Brasília (UnB) - Brasília (DF), Brazil.

C2015 by Anais Brasileiros de Dermatologia 
in one of the four major groups according to the place of formation of blisters: intraepidermal (EB simplex), inside (junctional EB), below the basement membrane zone (dystrophic EB), and with a mixed pattern (Kindler syndrome). ${ }^{5}$ The next step considers the phenotypic characteristics such as distribution (localized or generalized) and severity of cutaneous and extracutaneous involvement. ${ }^{5}$ The third step is based on the transmission mode and is identifiable by the specific gene involved, determined by means of immunohistochemical techniques and mutation analysis. ${ }^{5}$

This work aims to contribute to the analysis of the relation between the nutritional, hematologic, and infectious characteristics, as well as the type of EB, which can provide better therapeutic approach and quality of life for patients and their caregivers.

This is a descriptive case study based on data from medical records of 10 patients with EB, assist- ed regularly at the Dermatology Clinic of the Hospital Universitário de Brasilia. The old classification of the type of EB, weight and height, blood count, white blood cell count, platelet count and description of the type and frequency of secondary infections throughout the service were considered. Tables 1, 2 and 3 correlate patients and their respective data.

There was a predominance of chronic malnutrition, low height for age and thinness, and patients with EB simplex presented appropriate relation between height/age and BMI/age. Also, there was a predominance of cases of iron deficiency anemia, chronic leukocytosis and thrombocytosis without direct correlation to the type of EB. Nonspecific skin infection was the most prevalent in both sexes. Severity of the type of EB and frequency of secondary infections did not form a directly proportional relation.

TABle 1: Age (years) during the survey period (March 2013), sex, type of EB, total time of assistance (years) and total infections in patients with epidermolysis bullosa followed at the Dermatology Clinic of the Hospital Universitário de Brasília (HUB)

\begin{tabular}{llllll}
\hline Patient & Age & Sex & Type of EB & Time & Total infections \\
\hline P1 & 19 & F & Recessive dystrophic & 19 & 0 \\
P2 & 8 & F & Recessive dystrophic & 9 & 7 \\
P3 & 7 & M & Simplex & 12 & 7 \\
P4 & 11 & M & Recessive dystrophic & 3 & 2 \\
P5 & 12 & F & Recessive dystrophic & 8 & 2 \\
P6 & 8 & M & Simplex & 19 & 15 \\
P7 & 18 & M & Recessive dystrophic & 12 & 21 \\
P8 & 14 & F & Recessive dystrophic & 16 \\
P9 & 13 & F & Junctional or dystrophic & 1 \\
P10 & 15 & F & Dominant dystrophic & 10
\end{tabular}

Male (M); Female (F).

TABLE 2: Weight $(\mathrm{kg})$, height $(\mathrm{m})$, BMI $(\mathrm{kg} / \mathrm{m} 2)$ at the end of the survey period (March 2013) and relations between height and age (H/A) and body and body mass index and age (BMI/A) in patients with epidermolysis bullosa followed at the Dermatology Clinic of the Hospital Universitário de Brasília (HUB)

\begin{tabular}{|c|c|c|c|c|c|c|c|}
\hline Patient & Age & Sex & Weight & Heigh & BMI & H/A & BMI/A \\
\hline P1 & 19 & F & 27 & 1,5 & 12 & $<\mathrm{p} 3$ & $<\mathrm{p} 3$ \\
\hline P2 & 8 & F & 16,3 & 1,15 & 12,32 & $<\mathrm{p} 3$ & $<\mathrm{p} 3$ \\
\hline P3 & 7 & M & 29,7 & 1,38 & 15,59 & p97 & p15-50 \\
\hline P4 & 11 & M & 22,9 & 1,36 & 12,38 & p3-15 & $<\mathrm{p} 3$ \\
\hline P5 & 12 & F & 20,9 & 1,31 & 12,17 & $<$ p3 & $<\mathrm{p} 3$ \\
\hline P6 & 8 & M & 30,2 & 1,43 & 14,76 & p97 & p15-50 \\
\hline P7 & 18 & M & 35,2 & 1,61 & 13,57 & $<$ p3 & $<\mathrm{p} 3$ \\
\hline P8 & 14 & F & 17,2 & 1,22 & 11,55 & $<$ p3 & $<\mathrm{p} 3$ \\
\hline P9 & 13 & F & 25,7 & 1,28 & 15,68 & $<$ p3 & $<\mathrm{p} 3$ \\
\hline P10 & 15 & F & 41,8 & 1,6 & 16,32 & p15-50 & $<\mathrm{p} 3$ \\
\hline
\end{tabular}

BMI: body mass index 
TABLE 3: Distribution of infections recorded since the start of the care of patients until the end of the survey period (March 2013) of patients with epidermolysis bullosa followed at the Dermatology Clinic of the Hospital Universitário de Brasília (HUB)

\begin{tabular}{lllcllclllcc}
\hline Patient & URI & PA & Moniliasis & Otitis & PNM & Skin infection & Myiasis & UTI & Balanoposthitis & AGEC & Oxyuriasis \\
\hline P1 & 0 & 0 & 0 & 0 & 0 & 0 & 0 & 0 & 0 & 0 \\
P2 & 0 & 0 & 0 & 0 & 0 & 3 & 0 & 0 & 0 & 0 \\
P3 & 0 & 0 & 0 & 0 & 0 & 7 & 0 & 0 & 0 & 0 \\
P4 & 0 & 0 & 1 & 0 & 0 & 1 & 0 & 0 & 0 & 0 \\
P5 & 1 & 0 & 0 & 0 & 0 & 5 & 0 & 0 & 0 & 0 \\
P6 & 0 & 0 & 0 & 0 & 0 & 2 & 0 & 0 & 0 & 0 \\
P7 & 0 & 0 & 0 & 1 & 1 & 6 & 1 & 0 & 0 & 0 \\
P8 & 0 & 3 & 2 & 1 & 2 & 8 & 0 & 3 & 0 & 0 \\
P9 & 0 & 0 & 0 & 0 & 0 & 11 & 1 & 4 & 0 & 0 \\
P10 & 0 & 0 & 0 & 0 & 0 & 0 & 0 & 0 & 0 & 0 \\
\hline
\end{tabular}

URI: upper airway infection; PA: Pharyngoamigdalitis; PNM: Pneumonia ; UTI: Urinary tract infection; AGEC: acute gastroenterocolitis

Absence of direct proportion in all cases between the type of EB and analysis parameters suggest a possible significant interference from other aspects such as the extent of the affected skin area, extracutaneous involvement and type of specific genetic mutation. Inclusion of these factors in the new classification proposed by Fine et al can contribute significantly to a better correlation of clinical parameters and appropriate preventive and therapeutic approaches.

Due to the rarity of the disease, the number of cases studied was small and further studies are needed to better evaluate the data found.]

\title{
REFERENCES
}

1. Sawamura D, Nakano H, Matsuzaki Y. Overview of epidermolysis bullosa. J Dermatol. 2010;37:214-9.

2. Langan SM, Williams HC. A systematic review of randomized controlled trials os treatments for inherited forms of epidermolysis bullosa. Clin Exp Dermatol. 2009;34:20-5.

3. Barbosa GCT, Albertini Junior J, Oliveria ZNP, Machado MCR, Assumpção IGR Epidermólise bolhosa distrófica e juncional: aspectos gastrointestinais. Pediatria (São Paulo). 2005;27:87-94.

4. Alves PVM, Alves DKM, Maciel JVB, Bolognese AM. Atendimento multidisciplinar do paciente ortodôntico com epidermólise bolhosa. $\mathrm{R}$ Dental Press Ortodon Ortop Facial. 2007; 12:30-5.

5. Fine JD, Bruckner-Tuderman L, Eady RA, Bauer EA, Bauer JW, Has C, et al. Inherited epidermolysis bullosa: Updated recommendations on diagnosis and classification. J Am Acad Dermatol. 2014;70:1103-26.

\author{
MAILING ADDRESS: \\ Márcia Carolline dos Santos Sousa \\ Ambulatório de Dermatologia do Hospital Universitário de \\ Brasília, SGAN 605 \\ Av.L2 norte - Brasília, - DF \\ Brazil \\ Email:mcss_med@hotmail.com
}

How to cite this article: Sousa MCS, Paula CDR, Tauil PL, Costa IMC. Correlation between nutritional, hematological and infectious characteristics and classification of the type of epidermolysis bullosa of patients assisted at the Dermatology Clinic of the University Hospital of Brasilia. An Bras Dermatol. 2015; 90(6):922-4. 